\title{
Disciplinamiento y fuga. Subjetividades de trabajadores migrantes mexicanos en Nueva York
}

\author{
Blanca Laura Cordero Díaz
}

\section{Resumen}

Este artículo muestra el carácter contradictorio en las subjetividades que ponen en juego migrantes mexicanos de origen rural al insertarse mayoritariamente al mercado de trabajo de los restaurantes y a la vida en Nueva York. Teniendo "el poder despótico del capital" y la "fuga" del "trabajo vivo" como ejes polares de las relaciones de poder en las que se mueven los migrantes, se muestra, con base en un caso etnográfico, que las subjetividades y las prácticas nunca se mueven en un sólo sentido de estos polos, sino que están atravesadas por el antagonismo. Así, se analiza cómo los migrantes se disciplinan, al mismo tiempo que desafían el carácter embridado del trabajo que realizan en los restaurantes, donde la disposición y explotación de su mano de obra se produce por una combinación de ilegalización, precarización y subjetivación. En consecuencia, se presentan distintos sentidos de "fuga" desde el punto de vista de las visiones de los migrantes en torno a la subordinación y a la disciplina del trabajo en Nueva York, en contraposición a la subordinación del trabajo campesino en su localidad de origen, desde el punto de vista de un campo multipolar de defección y sustracción, en donde las "fugas" parecen más las marcas de un proceso tenso y contradictorio de transiciones constantes, que líneas unidireccionales de huida.

\section{Palabras clave}

Migrantes; Subjetividades; Trabajo embridado; Trabajo vivo; Fuga.

*Blanca Laura CORDERO DÍAZ, Profesora Investigadora a tiempo completo. Instituto de Ciencias Sociales y Humanidades de la Benemérita Universidad Autónoma de Puebla.

\section{Recibido:}

2017-04-22

Aceptado:

2017-10-10

DOI: $10.15366 /$

relacionesinternacio nales2017.36.008

\section{TitLe}

Discipline and Escape. Mexican Migrant Workers' Subjectivities in New York

\begin{abstract}
This article deals with the contradictory nature of the subjectivities that mexican rural migrants in the United States put into play as they join the catering industry labor market and social life in New York. Considering the 'despotic power of capital' and the 'flight' of active labour as two poles of power relations in which migrants feature, this paper will show that the subjectivities and practices never move in one direction within these poles, but that they are crossed through with antagonism. Thus, the analysis will concern how migrants are disciplined, as they defy the restrained character of the work they carry out in the restaurants, where the disposition and exploitation of their labour is produced by a combination of illegality, precarity, and subjectivization. As a consequence, different meanings of 'flight' are introduced from the point of view of the migrants and in relation to the subordination and the discipline of the work in New York. This can be contrasted with the subordination of the rural work in their place of origin, from the viewpoint of a multipolar field of defection and subtraction, where the 'flight' appears to be more the marking of a tense and contradictory process, than a one-directional line of escape.
\end{abstract}

\section{KeYWORDS}

Migrants; Subjectivities; Flanged labour; Living labor; Escape. 


\section{ntroducción}

El aumento sin precedentes a nivel mundial de las migraciones indocumentadas y la emergencia de nuevas modalidades migratorias ${ }^{1}$ deben ser entendidos en el seno de una nueva formación global capitalista ${ }^{2}$. En diferentes escalas y particularidades, a partir de la crisis económica de los años setenta, el mundo asistió a la reconfiguración de las coordenadas espacio-temporales de las relaciones productivas, la aparición de combinaciones inéditas de mecanismos de explotación del trabajo y formas de acumulación de capital ${ }^{3}$. El despliegue de nuevas formas de acumulación ${ }^{4}$, que dieron como consecuencia la proletarización precaria de miles de campesinos y el despojo de medios de vida en espacios agrarios y ciudades en los países periféricos de la economía capitalista, así como la terciarización de las economías centrales y el repunte de sectores de la economía altamente tecnológicos, han estado detrás de nuevas formas de movilidad de capitales y de mano de obra global ${ }^{5}$.

Diversos estudios y aproximaciones teóricas a las migraciones nos han mostrado el lugar de los migrantes en las economías capitalistas: su calidad de mano de obra barata, ilegalizada, generizada y racializada ${ }^{6}$. A pesar de las innegables relaciones constitutivas entre las migraciones recientes y estos aspectos claves de los mercados de trabajo en la globalización contemporánea7, si sólo apuntamos esta dimensión coercitiva y estructurante de las prácticas sociales por el capital, dejamos de observar las capacidades creativas de las personas migrantes y las formas en las cuales interpelan de distintas maneras las fuerzas sociales globales.

En el marco de los estudios sobre las migraciones, la teoría de las redes sociales, la visión feminista y el transnacionalismo han dado elementos para analizar a los sujetos actuando en estas tramas coercitivas ${ }^{8}$. Sin embargo, desde la perspectiva de este trabajo,

1 No obstante, es díficil saber lo que la migración indocumentada aporta al crecimiento absoluto del volumen de migrantes en el mundo registrados a partir de la pirmera guerra mundial; Castles y Miller afirman al respecto: "hay muchas razones para creer que la migración ilegal ha crecido agudamente en décadas recientes. De ahí que la afirmación de que en el mundo moderno no se ha experimentado un crecimiento notable en la migración internacional; basada en la comparación de las estadísticas de los dos periodos, debe rechazarse. Buena parte de la migración internacional contemporánea simplemente ha quedado sin registrar y no se refleja en las estadísticas oficiales". CASTLES, Stephen H. de H. y MILLER, J. Mark, La era de la migración. Movimientos internacionales de la población en la era moderna, Universidad de Zacatecas, INM, Miguel Ángel Porrúa, México, 2004, p.5.

2 Para una reflexión entre globalización y migración desde el punto de vista de nuevas formas de ciudadanía, véase, ESTÉVEZ, L. Ariadna, "La relación estructural entre la globalización y la migración. Implicaciones para una ciudadanía universal" en Foro Internacional, Vol. XLIX, No 3, México, 2009, pp. 559-594.

3 HARVEY, David, La condición de la posmodernidad. Investigación sobre los orígenes del cambio cultural, Amorrortu Editores, Buenos Aires, 1998 [1990].

4 HARVEY, David, El nuevo imperialismo, Akal, Madrid, 2003.

5 SASSEN, Saskia, Contrageografías de la globalización. Género y ciudadanía en los circuitos transfronterizos, Traficantes de Sueños, Madrid, 2003.

6 Véase CANALES, Alejandro, "Migración y trabajo en la era de la globalización: el caso de la migración mexicana a Estados Unidos en la década de 1990" en Papeles de población, Vol. 11, No 43-44, 2002, pp. 149-172; ARAGONÉS, Ana María y SALGADO, Uberto, "La migración en los albores del siglo XXI. El caso México Estados Unidos" en Crítica y Emancipación, Año II, Vol. 1, Primer semestre, 2011; MOLINERO, Yoan y AVALLONE, Gennaro, "Produciendo comida y trabajo baratos: migraciones y agricultura en la ecología mundo capitalista" en Relaciones Internacionales, No 33, 2016: http://www.relacionesinternacionales.info/ojs/article/view/731. html [Consultado 8 de abril de 2017]; SASSEN, Saskia, Contrageografías de la globalización..., op.cit.; y CASTLES, Stephen H. de H. y MILLER, J. Mark, The new age of migration. International population movements in the modern era, Palgrave MacMillan, Londres, 2014 [5a edición].

7 Véase SASSEN, Saskia, Contrageografías, op.cit. y CASTLES, Stephen H. de H. y MILLER, J. Mark The new age of..., op.cit.

8 Véase BASCH, Linda et al., Nations Unbound. Transnational Projects, Postcolonial Predicaments and 
sí interesa resaltar cómo se lleva a cabo la explotación laboral cotidianamente y cómo se subjetivan los trabajadores migrantes a sí mismos en el mercado laboral y en el orden social en tanto fuerza de trabajo, y cómo, al mismo tiempo, critican y desafían esta condición. Necesitamos pensar en sujetos migrantes construidos en el antagonismo social ${ }^{9}$ y considerar el carácter tenso y dinámico, así como los elementos de subjetivación que están presentes en el movimiento social de las migraciones. Ello parece complicado sin virar hacia una posición cargada al lado de la "agencia", o bien, hacia una en la que sólo encontramos sujetos allí donde se ven claras muestras de desobediencia deliberada y organizada a los controles de las fronteras y las restricciones de los derechos políticos y sociales en las sociedades receptoras.

En el nivel más general, en este artículo trato el carácter complejo y contradictorio de los procesos de subjetivación que los migrantes ilegalizados muestran alrededor del trabajo en el capitalismo contemporáneo en una ciudad global. Concretamente, el objetivo es captar a nivel empírico, por medio de técnicas etnográficas, las relaciones de antagonismo social que marcan la experiencia social y laboral de migrantes mexicanos trabajadores en Estados Unidos. Subrayo el carácter ambiguo y contradictorio en las subjetividades que ponen en juego los migrantes al insertarse a los mercados de trabajo y a la sociedad estadounidense.

La investigación que nutre las reflexiones teóricas versa sobre migrantes poblanos indocumentados que laboran mayoritariamente en el sector servicios, y más precisamente, en la industria de los restaurantes en Nueva York ${ }^{10}$. Las realidades objetivas de los migrantes, a partir de las cuales construyo mi argumento, forman parte de un contingente nutrido de trabajadores cuyas condiciones de explotación, disciplinamiento y reproducción social son fundamentales para la economía y competitividad de la industria restaurantera en la ciudad global ${ }^{11}$. En la primera parte del trabajo analizaré las tensiones entre el disciplinamiento y las

Deterritorialized Nation States, Gordon and Breach, Nueva York, 1994; GOLDRING, Luin, "Blurring Borders: Constructing Transnational Community in the Process of Mexico-US Migration" en Research in Community Sociology, Vol. 6, Jai Press, 1996; PRIES, Ludger, Migration Transnational Social Space, Ashgate Publishing Ltd, Farnham, 1999; HONDAGNEU-SOTELO, Pierrette, Gendered Transitions: Experience of Inmigration, University of California Press, California, 1994.

9 Aquí el antagonismo social, refiere a la tensión constitutiva entre capital-trabajo en las sociedades capitalistas, en la cual se abunda más adelante, recuperando la diada capital abstracto como par antagónico del trabajo vivo. Se concibe el antagonismo social constituido por procesos abiertos. Para una revisión del concepto de antagonismo social desde una posición contemporánea de Marxismo crítico, véase el prólogo y los ensayos compilados en HOLLOWAY, John, Clase = Lucha. Antagonismo social y marxismo crítico, BUAP, Herramienta, México-Argentina, 2004.

${ }^{10}$ La investigación que respaldan las reflexiones teóricas y datos utilizados en este artículo fue realizada a través de técnicas etnográficas y la aplicación de una encuesta en la localidad migrante de donde proceden los sujetos de estudio y en Nueva York, con varios periodos de trabajo de campo entre 2000-2003, 2006 y 2010. En particular, se utilizan datos de una encuesta que se realizó en la localidad de estudio durante el 2003 y 2004 a una muestra de 75 familias elegidas por muestreo probabilístico. Huaquechula, localidad de estudio, se encuentra ubicada en la región agrícola del Valle de Atlixco en el estado de Puebla, en la zona central de México. El cuestionario recogió datos sobre la experiencia migratoria del jefe de familia y los integrantes del grupo doméstico, así como de todos los miembros de la familia, aun aquellos viviendo en Nueva York. Adicionalmente se realizaron entrevistas en profundidad, reconstruyendo trayectorias laborales. Se compararon los resultados de investigación con los que arrojó la tesis doctoral: GUZMÁN, A., José, ¿Ilegal-es? vivencias de Huaquechula en un barrio latino y un suburbio en Nueva York dentro de relaciones hegemónicas y flexibilidad laboral, dirigida por Blanca Laura Cordero Díaz, ICSYH-AVP-BUAP, México, 2014.

11 Véase, por ejemplo, CANALES, Alejandro, "Migración y trabajo en la era de la globalización...", op.cit., sobre el papel de la exportación de la mano de obra en la economía mexicana; GLEDHILL, John, Neoliberalism, transnationalism and rural poverty. A case study of Michoacán, México, Westview, Estados Unidos, 1995, acerca de la relaçión entre mano de obra mexicana y reestructuración de la economía estadounidense; PARRA, José María y GÁMEZ, Emilia, "Situación de la fuerza de trabajo en Estados Unidos" en BENENCIA, R., HERRERA, F., y LEVINE E., (Coords.), Ser migrante latinoamericano, ser vulnerable, trabajar precariamente, ANTHROPOS-UAM, 
fugas en el trabajo "embridado" de los restaurantes ${ }^{12}$. En la segunda parte abordaré la fuga desde el punto de vista de la crítica que los migrantes realizan al trabajo dependiente ${ }^{13}$ desde una subjetividad que transita entre el cuestionamiento al trabajo "sucio" del campo mexicano a una crítica de la vida de "puro trabajo", en la que se advierte la conciencia de un proceso social contradictorio en que el trabajo vivo - capacidades físicas, sociales, intelectuales- se va poniendo bajo el mando del capital en Nueva York.

Recupero planteamientos y conceptos de una perspectiva marxista renovada sobre las migraciones y de una perspectiva particular de la autonomía de las migraciones. Esta perspectiva le confiere un papel central a la subjetividad para entender los movimientos migratorios; sin embargo, las relaciones capital-trabajo, es decir, el antagonismo social que atraviesa a tales movimientos, no se pierden de vista en su comprensión ${ }^{14}$. Intento aportar con el análisis de datos empíricos de corte cualitativo a una agenda de investigación que resumo en la siguiente cita de Sandro Mezzadra sobre su propia elaboración de la autonomía de las migraciones:

"Significa observar los movimientos y conflictos migratorios de modo que se priorizan las prácticas subjetivas, los deseos, las expectativas y los comportamientos de los migrantes mismos. Ello no implica una idealización de la migración, en tanto que la ambivalencia de estas prácticas subjetivas y comportamientos siempre está presente. Nuevos dispositivos de dominación y de explotación se forjan en la migración considerada como movimiento social, así como nuevas prácticas de igualdad y libertad"15.

La tensión entre el despotismo y la fuga que caracterizan las relaciones capital-trabajo "recorre toda la historia del modo de producción capitalista"16. El capital necesita la creación de una fuerza de trabajo que requiere disciplinar y explotar, y para ello convierte el trabajo vivo en trabajo abstracto. Plantear la tensión constitutiva de las migraciones contemporáneas entre el poder despótico disciplinario del capital ${ }^{17}$ y la fuga, implica una concepción crítica acerca de los sujetos migrantes, vistos en antagonismo con las fuerzas sociales, los mecanismos

México, 2012, sobre la composición de la "fuerza de trabajo transnacional mexicana" en los sectores económicos, en la Población Económicamente Activa y en las diferentes ramas productivas.

${ }^{12}$ El trabajo embridado es definido por Yann Moulier-Boutang como trabajo sólo parcialmente libre. El autor se refiere a la importancia que ha tenido históricamente para el capital "fijar" al trabajador bajo su mando por diversos mecanismos que limitan su movilidad. En el caso del trabajo indocumentado en los restaurantes que se analiza en este artículo, estaríamos hablando de un trabajo que se mantiene en condición de solo parcialmente libre (embridado) a través del mecanismo de su discriminación legalizada (a través de la ilegalización de los migrantes) y de procesos subjetivos que lo hacen posible. Véase MOULIER-BOUTANG, Yann, De la esclavitud al trabajo asalariado. Economía histórica del trabajo asalariado embridado, Akal, Madrid, 2006, p. 29.

13 Trabajo dependiente es definido por Yann Moulier-Boutang como la "capacidad de trabajar de un individuo que sólo dispone de ella para vivir", la cual pone a disposición del empleador, "quien tiene la autoridad relativa a la división y organización del trabajo". Véase MOULIER-BOUTANG, Yann, De la esclavitud al trabajo asalariado... op.cit., p. 354-355.

${ }^{14}$ Véase DE GENOVA, P., Nicholas, "The everyday civil war: Migrant working men, within and against capital" en Ethnography, Vol. 7, № 2, Junio 2006, pp. 243-267.

15 MEZZADRA, Sandro, "¿Cuántas historias del trabajo? Hacia una teoría del capitalismo poscolonial" en Transversal, 01-12, 2012: http://eipcp.net/transversal/0112/mezzadra/es [Consultado 2 de abril de 2016]

${ }^{16}$ MEZZADRA, Sandro, Derecho de fuga. Migraciones, ciudadanía y globalización, Traficantes de sueños, Madrid, 2005, p. 87.

17 Se entiende el poder despótico del capital como la capacidad de los dueños de los medios de producción para imponer su mando y disciplina sobre los trabajadores, más allá de la oferta de un salario. 
económico-políticos, la violencia y la disciplina que impone el capital. De tal modo que los sujetos que se movilizan y dan formas sociales y políticas diversas a las migraciones actuales no son vistos sólo en su carácter de individuos y colectividades que poseen emociones, voluntades, que realizan cálculos, que producen cultura, sino también en su condición de sujetos que se constituyen en el antagonismo social. Mezzadra entiende este antagonismo, recuperando a Chakrabarty, a través de la tensión social que nombra la oposición entre "trabajo abstracto" y "trabajo vivo"18.

El concepto de trabajo abstracto formulado por Marx alude a la propiedad "abstracta" que necesita tener el trabajo en el capitalismo: "Todo trabajo es, por un lado, gasto de fuerza humana de trabajo en un sentido fisiológico, y es en esta condición de trabajo humano igual, o de trabajo abstractamente humano, como se constituye el valor de la mercancía"19. Desde este punto de vista la necesidad de crear un trabajador bajo el mando del capital implica la necesidad de construir sujetos en torno a esa propiedad abstracta, es decir, sujetos cuya capacidad de trabajo adquiera la forma de cualquier otra mercancía. En resumen, significa la abstracción que se hace de las demás fuerzas vitales humanas para extraer sólo la que añade valor al proceso de producción de bienes, servicios y conocimientos. El concepto de trabajo vivo remarca las subjetividades en tensión que se encuentran en el corazón de los procesos que hacen posible o dificultan la abstracción del trabajo.

Teniendo "el poder despótico del capital" y la "fuga" del "trabajo vivo" como ejes polares de las relaciones de poder en las que se mueven los migrantes, intentaré mostrar en el análisis que las subjetividades y las prácticas nunca se mueven en un sólo sentido de estos polos; por tal motivo es necesario registrar a nivel empírico sus expresiones ambiguas y a veces simultáneas.

\section{Poder despótico del capital y disciplinamiento. Trabajo embridado en los restaurantes de Nueva York}

"El poder despótico del capital" es un concepto que se refiere a la capacidad del capital de poner bajo su mando a los trabajadores por medio de una disciplina que implicó en los albores de la modernidad violencia y "encierro". Ello supone - dice Mezzadra ${ }^{20}$, retomando a Yann Moulier Boutang - que el trabajo no libre, o embridado (trabajo parcialmente libre), fue fundamental en la conformación de los mercados de trabajo.

Tomo esto como un punto de partida teórico para explorar la idea de que justamente lo que observamos en el mercado de trabajo de los restaurantes es un trabajo embridado, es

\footnotetext{
18 Mezzadra retoma esta reformulación de Chakrabarty sobre la oposición planteada por Marx entre trabajo concreto y trabajo abstracto; contraposición íntimamente ligada con las propiedades de valor de uso y valor de cambio de la mercancía. Véase MEZZADRA, Sandro, "Living in transition" en Transversal, Vol. 11-07, 2007: http://translate.eipcp.net/transversal/1107 [Consultado 20 de noviembre de 2015].

19 MARX, Karl, El capital. Crítica de la economía política. Tomo I. El proceso de producción de capital, Siglo XXI, México, 2001 [1975], p. 57.

20 Mezzadra, Sandro, Derecho de fuga..., op.cit.
} 
decir, "trabajo parcialmente libre"21, producto de las leyes que crean su ilegalización²2, donde la disciplina espacial y temporal no es el encierro literal, que crea el efecto de mantener fijada la mano de obra para disponer de ella, sino lo que produce este efecto es la combinación de ilegalización con precarización y la subjetivación de estas condiciones por parte de los migrantes ${ }^{23}$. En la experiencia laboral de los migrantes, la disponibilidad de una mano de obra que se disciplina está estrechamente ligada a las condiciones de contratación de los trabajadores, en las que su condición ilegalizada y su subjetivación juegan de manera central. Los trabajos en los restaurantes son masculinizados, la mayoría se emplea por medio de conocidos, sin documentos, mediante acuerdos de palabra, con pagos en efectivo y con registros falsos o sin registro en las nóminas y el sistema de seguridad social. Los migrantes relatan la existencia de condiciones de trabajo caracterizadas por sueldos sub remunerados y constantemente aparece en sus testimonios cómo laboran horas de trabajo sin pago, así como el hecho de que deben estar al pendiente de las exigencias de los dueños de los establecimientos para poder sostener su trabajo.

La industria restaurantera en Nueva York ha crecido a la par del sector servicios en esa ciudad y de la economía terciaria de Estados Unidos desde mediados de la década de los setenta. La conversión de Nueva York en un centro de negocios global propició el ensanchamiento de un mercado laboral de servicios, con una mano de obra caracterizada por sus bajos niveles de calificación y sus bajas percepciones salariales. El negocio de los restaurantes, en sus diferentes segmentos - pequeños, independientes, grandes cadenasse caracteriza por su alta competitividad, que depende en gran medida del corte de costos en la mano de obra, en la medida en que los costos de los insumos para la elaboración de comida son más o menos fijos y la inversión tecnológica es mínima comparada con otro tipo de empresas. No sorprende que los migrantes mexicanos hayan conquistado como uno de sus nichos laborales en Nueva York el empleo en los restaurantes, desplazando a los asiáticos que dominaban este segmento del mercado de trabajo hasta los años cincuenta; ello en un país donde la industria de los servicios de comida emplea a un inmigrante por cada cinco trabajadores que ocupa y sus negocios se han vuelto dependientes de mano de obra barata ${ }^{24}$.

${ }^{21}$ Este concepto se encuentra relacionado con los amarres sistemáticos a la movilidad del trabajo, como se menciona en una nota anterior. Véase MOULIER-BOUTANG, De la esclavitud al trabajo asalariado... op.cit., p. 29.

22 Nicholas P. de Genova plantea que la "ilegalidad" migrante es producto de la ley y se sostiene por el efecto de una formación discursiva. DE GENOVA, P., Nicholas, "Migrant 'Illegality' and deportability in everyday life" en Annual Review Anthropology, Vol. 31, Universidad de California, 2002, p. 431.

${ }^{23}$ Alejandra Aquino tiene un trabajo de carácter etnográfico con migrantes jóvenes zapatistas que oscilan entre ser "Trabajo cautivo" y "nómadas laborales"; retomando a Yann-Moulier Boutang, se refiere al trabajo cautivo para captar "el encierro" que experimentan estos jóvenes en el mercado laboral en ciertos momentos. Véase AQUINO, Liliana, "La migración de jóvenes zapatistas a Estados Unidos como desplazamiento geográfico, político, subjetivo" en European Review of Latin American and Caribbean Studies / Revista Europea de Estudios Latinoamericanos y del Caribe, № 92, Centrum voor Studie en Documentatie van Latijns Amerika (CEDLA), 2012, pp.3-22.

${ }^{24}$ Véase el reporte sobre trabajo no regulado en la ciudad de Nueva York en BERHARDT, Annete, MC GRATH, Siobhán y DE FILIPPIS, James, Unregulated work in Global City. Employment and labor law violations in New York City, Brenner Center for Justice, New York University School of Law, Nueva York, 2007, pp. 53-56. En este documento se describen condiciones de trabajo de la industria de los restaurantes -en la que los trabajadores mexicanos e indocumentados están sobrerepresentados- idénticas a las que relatan los migrantes entrevistados en la localidad poblana y la ciudad de Nueva York protagonistas de nuestra investigación: jornadas laborales de 50 horas semanales como mínimo, salarios por debajo del mínimo, trabajo impago, horas extras no remuneradas, maltrato y racismo en la jerarquía de los puestos de trabajo, entre las más importantes. 
Es en este contexto que los migrantes han construido disciplinas diarias para adaptarse a las jornadas laborales más allá de las doce horas diarias, a los descansos mínimos, a la polivalencia de labores, al trabajo sin pago que ha crecido en momentos de crisis como el 11 de septiembre de 2001 y la crisis financiera de 2007, y a no protestar. No enfermarse, no faltar al trabajo, no embriagarse, son algunas formas de disciplinamiento que han construido los migrantes como comportamientos adecuados a sus condiciones de trabajo y a su situación migratoria, que por un lado implican la posibilidad permanente de ser despedidos y, por otro, la amenaza latente de ser deportado en las redadas a los centros de trabajo.

El caso de Jacinto concentra estas condiciones. Él salió a mediados de los ochenta hacía Nueva York; lo entrevisté en Huaquechula, Puebla, en 2005, cuando contaba con la edad de 52 años y había regresado para el funeral de su madre. En su condición de indocumentado, solía viajar, como la gran mayoría de sus paisanos, cada dos o tres años para las fiestas de navidad o semana santa, pero esta vez tuvo que venir en un periodo no vacacional, era septiembre. Me recibió en la sala de su casa, era espaciosa, como la mayoría de las casas que visité en Huaquechula. Me senté en su sofá y él paró las labores de remodelación que le realizaba a su casa. Se mostraba orgulloso de su casa y todos sus logros. Me contó que después de haber trabajado en los puestos más bajos en varios restaurantes en Nueva York, se había quedado en uno de ellos y permanecido durante 8 años. Me dijo que prácticamente podría considerarse el administrador, aunque su paga era la misma que cualquier otro trabajador en el puesto de cocina. Así como él, los más exitosos son aquellos que logran mantenerse por muchos años en un mismo negocio de comida. La permanencia les permite escalar de los puestos más bajos a los de mesero o ayudantes de cocina. Tanto jacinto como Tony, quien fue entrevistado en Nueva York y era también cuasi administrador de un restaurante, fueron dos de mis entrevistados más exitosos. Sólo que Tony es 10 años más joven y escaló más pronto, habiendo aprendido inglés. Los dos tienen vivencias parecidas, los dos me relataron cómo se tenían que quedar casi todos los días fuera de los horarios que se habían establecido y hacerse cargo de tareas diversas sin pago extra por ellas. Su éxito en la permanencia en su sólo puesto de trabajo, donde se mantuvieron en un nivel más alto de la jerarquía del puesto, se debía para ellos al hecho de haberse ganado la confianza del empleador. Aquí un pequeño fragmento de la entrevista con Jacinto, relatando cómo es que era un migrante exitoso:

J- Hay muchos que se emborrachan y faltan al trabajo y uno los tiene que cubrir.

B- ¿Le pagaban más por ello?

J- No, me pagan lo mismo, pero yo tengo las llaves del restaurant, el patrón me tiene mucha confianza, después de años que le he sido fiel.

La experiencia de Jacinto es un caso que muestra las dinámicas que caracterizan el trabajo no libre en estos mercados de trabajo, al no tener garantías legales ni derechos laborales. Jacinto pidió permiso para regresar a su tierra y faltar al trabajo quince días, porque su madre había fallecido, tenía que realizar trámites y organizar los rituales que se realizan en el pueblo cuando alguien fallece. Jacinto se quejó de que a pesar de tantos años trabajando en el mismo lugar y de ser de tanta confianza, y aún de haberse hecho indispensable, el dueño le acaba de llamar unas horas antes de mi llegada para que se regresara y le sugirió que si no regresaba pronto ya no le daría trabajo. 
Este caso ilustra que trabajar por muchos años, duro y abnegadamente con un mismo empleador no es mayor garantía para no perder el trabajo en caso de un imprevisto; ilustra, pues, que aquel que falta un lunes y se presenta el martes ya no tiene trabajo. Jacinto es un trabajador que por ocho años jamás faltó a su trabajo ni tomó vacaciones. Como él mismo me dijo "yo trabajo para matarme". "Trabajar para matarse" es una noción que registré en los discursos de mis entrevistados que me permitió distinguir una subjetividad y comportamiento disciplinado en el contexto de un trabajo precario, es decir, sin derechos ni garantías, que los coloca frente a frente a su empleador en condiciones de desventaja y bajo su plena autoridad, sin mediaciones legales.

La condición precaria e ilegal del trabajo coarta la movilidad de los migrantes en el mercado de trabajo, produciendo sensaciones de "quedar atrapados" 25 , en situaciones arbitrarias que sobre explotan su fuerza de trabajo. Pero también se observa cómo quedan "fijados" dentro del propio segmento de trabajo mal pagado. La posibilidad de moverse hacia puestos mejores en restaurantes mejores pagados a partir de su experiencia especializada como cocineros, por ejemplo, no existe para ellos. Este aspecto lo reveló muy bien la investigación de José Guzmán. Tal autor, con varios casos y relatos de migrantes de Huaquechula y otras nacionalidades en la industria de los restaurantes, expone cómo ser un chef de comida italiana, por ejemplo, no daba las credenciales para ganar lo que ganaba un chef con estudios o de nacionalidad estadounidense en un restaurante mejor pagado, según los testimonios de los propios migrantes ${ }^{26}$.

En el negocio de los restaurantes los dueños dejan a la responsabilidad individual de los trabajadores su condición legal. Los trabajadores o bien entran por recomendación de un amigo o bien consiguen documentos falsos. En particular, en los restaurantes no existe una exigencia rigurosa de documentación legal, la gran mayoría de dichos restaurantes que emplean indocumentados opera sin contratos y sin amparo del sistema de seguridad social, aunque existen también casos en que los migrantes aportan documentos apócrifos. Para los empleadores representa una ventaja no reportar a sus empleados en el sistema de seguridad social; y aunque para los migrantes representa la oportunidad de obtener trabajo con mayor facilidad que en otros tipos de empleo mejor pagados, llevan dos desventajas fundamentales: por un lado, dice uno de ellos "estamos fuera del sistema. Si trabajamos mucho o si ahorramos, eso no le importa al sistema, para el sistema no existimos". Esto quiere decir también que no tienen la posibilidad de que sus impuestos sean devueltos, de la misma manera que si trabajan con un número de seguridad social de otra persona legal "que puso sus papeles a trabajar". La otra desventaja consiste en que, además, el hecho de que sean trabajadores ilegalizados les pone una "brida" importante a su libertad de protesta. Es el caso que relata Antonio, encargado de cocina de un restaurante, donde varios huaquechulenses contrataron a un abogado para que el dueño les pagara un mes de deuda de salarios, y desistieron cuando el dueño los amenazó con reportarlos a las autoridades de migración ${ }^{27}$.

\footnotetext{
${ }^{25}$ En su investigación sobre migrantes Huaquechulenses en Nueva York, GUZMÁN, A., José, ¿Ilegal-es?..., op.cit., p.157, refiere a una frase testimonial de un migrante con el que subtitula uno de los acápites de su etnografía: "estamos atrapados en una jaula de oro".

${ }^{26}$ Ibídem, p. 150.

${ }^{27}$ Ibíd., p. 142.
} 
Las descripciones de los migrantes sobre sus condiciones de trabajo en ningún momento dejan de evidenciar arbitrariedades y malas condiciones. Pero sus relatos no sólo son siempre en esta dirección, puesto que siempre contienen elementos de valoración positiva. Sobretodo, el énfasis de sus testimonios está en el hecho de que pasar por alto las prácticas de explotación en este sector constituye su mayor ventaja como mano de obra frente a otros trabajos y otros trabajadores.

Los testimonios de los trabajadores, sus trayectorias laborales, así como sus experiencias en el sector de los restaurantes nos hablan de que las mismas condiciones que facilitan su explotación como mano de obra manejable a los intereses particulares del negocio de los restauranteros, también ejercen atracción. Observamos a través de las trayectorias diferentes movimientos en el mercado laboral, en los cuales los migrantes van adquiriendo experiencia para afrontar, de la mejor manera que pueden, sus condiciones desventajosas como indocumentados, con estrategias en las que conviven la conciencia crítica de ser explotados con un ejercicio limitado, pero importante, de su capacidad de movimiento para colocarse y sacar provecho de la condición en la que están.

Frente al trabajo de las maquilas donde el trabajo es a destajo y el control del trabajo es más rígido, con supervisores y jefes de piso, el empleo en los restaurantes es atractivo para los migrantes. Las razones que esgrimen los migrantes para justificar su empleo en el sector restaurantero destacan la posibilidad de empezar desde abajo en las jerarquías de los puestos, donde no se requiere calificación alguna, más que la de la disposición a cubrir un horario de trece o catorce horas diarias, lavando platos o sacando basura, para después escalar, aunque sea mínimamente, en los puestos de trabajo. Luego de esta inserción se abre el camino para ganar más, convirtiéndose en ayudantes de meseros, meseros o ayudantes de cocina. Esta trayectoria es la que más de la mitad de los entrevistados mostró28.

Otras ventajas que existen en el trabajo de los restaurantes tienen que ver con la capacidad de escaparse al control del trabajo estricto; como en la mayoría de ellos la contratación es por medio de otros trabajadores indocumentados, establecen relaciones de solidaridad que permiten la resistencia al control del trabajo. Sacar comida a escondidas de los dueños, beber o comer en el trabajo aún si no está permitido, son algunos de los comportamientos de fuga en el espacio laboral. Aunque $70 \%$ de los jefes de familia encuestados en la localidad tuvieron su primer trabajo en un restaurante, el otro 30\% usualmente llega a un trabajo en los sweatshops y busca llegar a limpiar platos, sacar basura o a desempeñarse como "libre" que hacen todo tipo de trabajo-. El fragmento de la siguiente entrevista con Joel ${ }^{29}$, empleado restaurantero, resume tanto el escape a otros trabajos con peores condiciones de trabajo, como la manera en que en los restaurantes el control del trabajo es más holgado y presenta mejores condiciones para ellos:

B: -¿Cuando llegó a trabajar en este país, en qué trabajó?

J: -Llegué a trabajar en una factoría en Brookling y era un poco difícil porque nos explotaban mucho y nos pagaban poco dinero (...) Estuve trabajando

${ }^{28}$ El $77.78 \%$ de los jefes de familia de los 75 hogares encuestados se emplearon en restaurantes en su primer viaje, de estos el $66.67 \%$ laboraron como lavaplatos o empleados libres, y el $3.70 \%$ se ocuparon en la cocina.

29 Joel (entrevista Nueva York 2004). 
solamente un mes y después de ahí me fui a trabajar a un restaurante mexicano y justo una semana después lo estaban cerrando y ya me estaba presentando en otro restaurante francés por recomendación de un amigo. "¿Sabes lavar platos?" -le preguntaron. "-Sí." -contestó. "-Está bien, vas a comenzar a trabajar, queremos ver como trabajas (...)". Era mucho mejor, era mejor dinero....Como era restaurant, podías a la hora que tú quisieras tomarte una soda o jugo; solamente trabajabas cuando estaba lleno de clientes, pero mientras no. Tú estabas tranquilo limpiando cualquier cosa, cubiertos, etcétera.

Así como Joel, otros migrantes me relataron que una de las ventajas de trabajar en la cocina es llevar comida para sus casas, sobre todo los fines de semana, a escondidas de los empleadores. Además, si no son ellos mismos los que lo hacen, sus amigos, familiares o paisanos reparten lo "saqueado" entre todos, formándose complicidades difíciles de romper.

No existen trayectorias uniformes, hay bastante movilidad de un trabajo a otro, aunque al menos la mitad de las trayectorias demostraron que la mayoría busca mediante diversas estrategias, como trabajar arduo y evitar confrontaciones con los dueños, permanecer en un mismo lugar por muchos años. Los más jóvenes que han terminado la educación básica e incluso hicieron algunos años de educación media, buscan adquirir habilidades en el idioma inglés, coreano o algún otro que se hable en el centro de trabajo, para ascender en menor tiempo a meseros o ayudantes de meseros y así dejar los puestos más bajos como saca comida, libres y lavaplatos, que son los puestos donde todos empiezan sus trayectorias laborales en los restaurantes. Pongamos dos ejemplos de trayectoria en ascenso:

B: - ¿En qué trabajas actualmente?

$\mathrm{RC}^{30}$ : -Soy mesero en un restaurante; dices los especiales, los ofreces, para que tú los vendas y ese es todo tu trabajo

B: - ¿Y cuánto ganas?

RC: -Como mesero gano un salario, además del $95 \%$ de las propinas.

B: -¿Cuántas horas al día trabajas?

RC: -11 horas, seis días a la semana.

B: -¿Cuánto tiempo llevas trabajando de mesero?

RC: -Dos años; antes trabajaba de ayudante de mesero, estuve así como tres años.

B: - ¿`Y en qué consistía tu trabajo?

RC: -Quitar y poner el servicio de las mesas

B: - ¿Y es mejor trabajar de mesero?

RC: -Sí, porque como ayudante sólo te toca el 5\% de las propinas y tenía que trabajar 13 horas diarias para sacar más dinero durante los horarios con más clientes.

B: -¿Cuáles han sido tus trabajos en Nueva York?

$\mathrm{RG}^{31}$-Te puedo enumerar muchos tipos de restaurantes en los que he

\footnotetext{
30 Roberto Cabrera (entrevista Nueva York 2004).
}

${ }^{31}$ Roberto Guzmán (entrevista Nueva York 2004). 
trabajado, italianos, franceses, pizzerías. Muchísimos, pero en la mayoría de estos lugares trabajé limpiando mesas, haciendo de "libres". Después de que yo estuve tres años en la escuela subi de mesero (...). Al principio cuando yo llegué me compre tres libros que venden en el puesto de revistas, me puse a estudiar frases, palabras como tenedor, cuchillo, plato, etcétera. Así estuve como por dos años. De ahí por medio de un amigo que me dijo: -"estudia mejor en una escuela, ahí aprendes mejor, te superas en todo los aspectos...", -entonces ya yo por mí mismo, fui a una escuela pública y me inscribí.

Sintetizando, lo que encontramos en el mercado laboral de los restaurantes es, por un lado, un espacio que se beneficia de los trabajadores ilegales, pues la falta de documentos o la entrega de documentos falsos coloca a los empleados en posición de desventaja para reclamar horas extras, trabajo impago, horarios fuera de lo acordado y malos tratos. Y por otra parte, observamos que los migrantes tienen comportamientos que muestran la subjetivización que realizan de su condición de ilegalidad y la forma en que asumen la explotación de su trabajo como un recurso en el mercado laboral en general.

Una categoría recurrente que salta como descubrimiento etnográfico en los testimonios recogidos en la investigación es la de "trabajar para matarse", sobre todo cuando se les preguntaba cuál era la clave de su permanencia como migrantes en el mercado laboral. Esta categoría solía salir cuando se comparaban con otros trabajadores, o cuando querían diferenciarse de trabajadores de otras nacionalidades. Es interesante que cuando se distinguen de otras nacionalidades resaltan el hecho de que los ciudadanos estadounidenses tienen prácticas laborales asociadas al sindicalismo. También trabajar para matarse se mencionaba cuando hablaban de los logros o los fracasos de migrar. De hecho, constituye una categoría etnográfica que muestra la subjetividad ambigua frente a la explotación del trabajo, desde el punto de vista de esta colectividad de migrantes, aquellos que tienen éxito, han ascendido porque "trabajan para matarse", mientras que otros trabajadores de otras nacionalidades no están dispuestos a eso. Al mismo tiempo muestran un escape constante de sus condiciones, en la búsqueda por mejores puestos dentro de los propios restaurantes y sacan provecho del mayor número de horas que pueden trabajar y de los momentos de resistencia al control del trabajo que pueden ejercer frente a los dueños, formando solidaridad entre ellos para comer y beber sin que medie un pago, que es de hecho una forma de complementación del salario.

\section{Fugas en varios sentidos. La crítica al trabajo dependiente.}

La fuga en la jerga de las migraciones connota éxodo, salida, desborde, fisura, su oposición al control, al límite y a los bordes. Los ejemplos históricos de la presencia de esta tendencia a la fuga conducen a cuestionarnos cómo entendemos la migración de los mexicanos a Estados Unidos. Si los migrantes de los albores de la modernidad huían del encierro, podríamos decir que existe una circunstancia análoga respecto de los mexicanos migrantes de la era del neoliberalismo y el capitalismo global.

Mezzadra, retomando la investigación de Linebaugh, señala:

[...] mientras que en las work houses, en las fábricas, en los hospitales, en las escuelas y en los grandes barcos de la marina atlántica, se realizaba

el encierro, fugas, deserciones, migraciones eran los comportamientos 
cotidianos del proletariado en formación para intentar eludir la imposición de una nueva norma de acumulación capitalista en su rígida disciplina temporal y espacial ${ }^{32}$.

Rastreando en la elaboración de Moulier Boutang sobre la importancia de las formas de "trabajo dependiente" en la instauración del modo de producción capitalista, Mezzadra dota de contenido a las migraciones en su carácter de "fuga" y afirma:

"La defección anónima, individual y colectiva, en la que hombres y mujeres intentan sustraerse al régimen despótico del trabajo dependiente, en las múltiples formas que esta asume, es de hecho elemento esencial de la relación social capitalista: la dinámica para entender los 'regímenes de acumulación' en el cual éste encuentra cada vez un equilibrio provisorio"33.

Los límites a la movilidad y el control del trabajo forman parte de la disciplina capitalista que se encuentra inevitablemente con estos movimientos de anónima defección. La movilidad del trabajo se presenta así como la "encarnación por excelencia de comportamientos de sustracción y fuga que la atraviesan subjetivamente" 134 .

Con más o menos un panorama completo de las causas documentadas de la migración mexicana en las últimas décadas, uno podría sospechar que los mexicanos huyeron de la imposibilidad de poder hacer una vida en sus propios términos. Podríamos documentar que huyeron de múltiples condiciones de subordinación social y económica en la que se encontraban. Y también que se fugaron de condiciones más particulares, como las mujeres y los jóvenes del poder patriarcal de sus familias, como los que declaran huir de la ignorancia, del encierro y de la imposibilidad de moverse libremente más allá de los confines de la localidad.

En términos generales, esta interpretación de la migración mexicana encaja con lo que Mezzadra remarca en relación con la fuga:

[...] el punto es subrayar el hecho de que para que las migraciones existan debe haber un movimiento individual [...] de deserción del campo donde las causas objetivas operan, haciendo valer precisamente su 'derecho a la fuga', aunque de manera inconsciente la mayor parte del tiempo, constituye una crítica a la división del trabajo internacional y marca profundamente la subjetividad de los migrantes también en los países en el que él o ella han decidido establecerse ${ }^{35}$.

A partir de este sentido de la fuga más abstracta, aquí me planteo explorar la fuga en un sentido dinámico y concreto para entender la cualidad de la fuga constante en la construcción de formas de vida transnacionales entre México y Estados Unidos. En su experiencia social los migrantes mexicanos se encuentran con un mundo plagado de dificultades y se enfrentan a

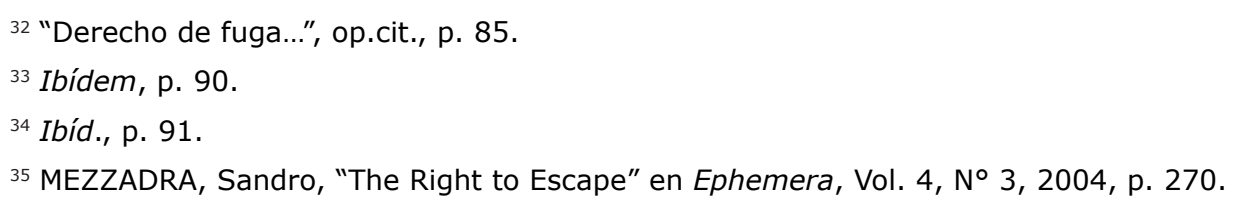


nuevas condiciones de subordinación, donde los sentidos de la fuga se construyen en campos sociales que rebasan los contextos sociales de dominio y subordinación de los que salieron y también sobrepasa los límites de aquellos hacia donde se mueven; por tanto, tal experiencia no puede verse en una sola dirección. En este apartado presento algunos sentidos de esta fuga desde el punto de vista de las visiones de los migrantes en torno a la subordinación y a la disciplina del trabajo dependiente en el sector de servicios de Nueva York, en contraposición a la subordinación del trabajo campesino en su localidad de origen, justo desde el punto de vista de un campo multipolar de defección y sustracción, en donde las "fugas" pueden parecer más las marcas de un proceso tenso y contradictorio, que líneas unidireccionales de huida.

Existen en los discursos de los migrantes de Huaquechula elaboraciones muy precisas sobre su condición de trabajadores y el carácter subordinado del trabajo que realizaban como campesinos en el Pueblo y el que realizan ahora para ganarse la vida en Nueva York. En las formulaciones discursivas que hacen sobre uno y otro tipo de trabajo lo que resalta justamente es la posición que ellos juegan en cada uno de ellos ${ }^{36}$.

"Estar a expensas"37 describe para los migrantes Huaquechulenses la condición de trabajo en la que ellos dependían de las situaciones azarosas, los vaivenes y la suerte del mercado agrícola local y regional que se empeoró durante la década de los años noventa con las reformas neoliberales mexicanas.

La generación de migrantes que entrevisté -que fue el cohorte migratorio de la época neoliberal en México-, a diferencia de sus padres, ya no poseían tierra ni trabajo asalariado estable en el campo. De tal modo que estas personas, sobre todo los varones, que fueron los primeros que salieron, describen su momento anterior a la migración como una situación de incertidumbre frente al trabajo. El Tratado de Libre Comercio de América del Norte (TLCAN) representó para el principal cultivo comercial de la micro región una caída de los precios y la pérdida de la importancia relativa que tenía la agricultura en la organización de la vida social ${ }^{38}$. Es interesante señalar que en realidad ellos nunca se consolidaron como proletarios urbanos en la economía doméstica. A pesar de que hubo presencia de migración interna sobre todo a la capital del estado de Puebla y al Distrito Federal, capital del país, ésta fue sumamente débil en comparación con el flujo que se iniciaría en los años setenta, y se mantiene hasta hoy -aunque con algunos cambios en los patrones de movilidad generados por el régimen de deportación- a Estados Unidos.

En este sentido podríamos decir que esta condición azarosa describe la volatilidad de un mercado de trabajo nacional que los mantenía en una posición cada vez más limitada y de mayor dependencia para ganarse la vida. De hecho, la frase "estar a expensas de" describe en el sentido común de esta región estar "a la expectativa de", "dependiendo de" factores externos. Estos otrora campesinos se convirtieron en el transcurso de unas décadas

${ }^{36}$ Algunos de los discursos presentados aquí los he analizado bajo una perspectiva teórica gramsciana. Véase CORDERO, Blanca, L., Ser Trabajador Transnacional. Hegemonía, clase y cultura en un circuito migratorio internacional, BUAP, CONACYT, México, 2007.

37 "Estar a expensas" fue la expresión que usaron muchos de mis entrevistados para referirse a depender de los vaivenes de la escasez del mercado agrícola de trabajo o de los ciclos agrícolas.

38 Véase Ibidem., p.133. 
en elementos no indispensables para las economías regionales mexicanas y descubrieron un mercado traspasando la frontera norteña, el cual robustecieron rápidamente junto con millones de contingentes de "despojados" de igual manera por las transformaciones en la geografía de las relaciones capital-trabajo de la economía globalizada.

Existe también otra dimensión social de la valoración negativa del trabajo campesino que los migrantes dejan ver en sus discursos y que se relaciona más con la construcción de identidades rurales "híbridas", resultantes de una modernidad vivida desde los márgenes en el campo mexicano del siglo XX. Los campesinos que mudaron a migrantes internacionales eran sujetos con aspiraciones de progreso en los términos dominantes. Los estilos de vida urbanos difundidos por la televisión o las incursiones en las ciudades cercanas, los motivaron a ir más allá de la vida rural en sus primeras incursiones a Estados Unidos. La idea sobre la buena vida no era vivir del campo, porque estar a expensas significaba también "trabajo sucio" 39 , de sol a sol.

Los migrantes describen con frecuencia el trabajo en el campo no sólo como un trabajo azaroso, mal pagado o inexistente, sino también degradado frente a los trabajos en la ciudad. Un trabajo "sucio" que por lo demás, no ofrecía opciones de sustento ni de futuro para sus hijos. Las metas educativas de los hijos, asociadas al papel que tuvo la educación en la movilidad social en el México de la post Revolución, es una de las razones que se repiten como motivación para la migración de huaquechulenses a Nueva York. Se valora entonces el trabajo en Nueva York desde la mirada de quien está gozando de una condición moderna negada en su país, la posibilidad de ser citadino, de tener un tiempo libre con su salario los domingos en sitios turísticos, de comer en restaurantes, de experimentar otras formas de socialidad. "Acá [en el campo] se sufre pero no se goza"40 es una frase que resume esta idea de cómo se huye de una condición negada y por otro lado se equipara el gozo con la incorporación a una vida citadina con la mediación del trabajo asalariado y la vida monetarizada. Como he descrito en otro trabajo ${ }^{41}$, el consumo moderno está en el centro de los discursos sobre los cambios más apreciados y fundamentales de la vida después de la migración.

En muchos sentidos, las explicaciones que los propios migrantes proveen y la articulación de estos discursos a procesos económico políticos globales coincidirían con la idea de fuga en el sentido más amplio que he expuesto líneas arriba. Lo que quisiera destacar es que esta línea de fuga del trabajo azarosos, sucio y degradado no es una huida en un solo sentido, por dos razones: la primera es que la vida del "trabajo a expensas" les provee a los migrantes huaquechulenses de una serie de experiencias sociales que les permite criticar también a la vida en Nueva York y construir líneas de fuga respecto de la misma. Los migrantes huaquechulenses refieren a su experiencia en la metrópoli norteamericana como de "puro trabajo" y con ello le asignan sentidos negativos a la incorporación plena al mercado de trabajo asalariado en el sector de servicios en Nueva York.

\footnotetext{
39 Varios de los entrevistados a profundidad en Huaquechula que habían retornado temporalmente de Nueva York se refirieron al trabajo agrícola como "trabajo sucio".

${ }^{40}$ Rigoberto (entrevista 2002, Huaquechula, Puebla).

${ }^{41}$ Ibíd.
} 
"La vida de puro trabajo" plasma plenamente la experiencia más generalizada de los migrantes mexicanos en Estados Unidos; es una expresión de mis entrevistados, pero la encontramos una y otra vez en los testimonios de muchos migrantes que han recabado diversas investigaciones.

B: -¿Qué es lo que más extraña de Huaquechula (México)?

J42: -La tranquilidad y la comida. Porque le digo, pues allá (Nueva York) es una vida de puro trabajar, comer y dormir. Porque allá no le da tiempo para sentarse un ratito en la cama, como ahora que se sentó usted aquí.

$B$ : -¿A qué hora se levanta usted?

J: -A las 4:20 am, me levanto, le hago café y su lunch a mi hijo. A veces me duermo otro rato y las 8 am me voy a trabajar y salgo de mi trabajo a las 6:30 pm. Llego a mi cuarto, aviento mi bolso y mi jacket y vamos para la cocina, calentamos comida, comemos. [Después de eso] me quedo haciendo la comida, arroz y un guisado para al otro dia ponerle el lunch a mi hijo y que nos quede comida. Y a trabajar otra vez. Todos los días igual. Los viernes descanso porque el sábado se compra su luch él [su hijo] allá.

$B$ : -¿A qué hora se duerme?

J: -A las 11:30 pm. Yo creo que por eso me siento mal.

Los migrantes describen el proceso de disciplinamiento en dos claves, la del ajuste corporal, mental y social a una forma de vida que ellos nombran colectivamente como de "puro trabajo" y, ligada a esta, "el progreso", "el éxito" que tiene un componente de nuevas formas de consumo que van reponiendo lo que ellos y ellas perciben como carencias que han tenido en su lugar de origen en México.

$\mathrm{O}^{43}$ : - Para hacer todo lo que uno quiere tiene que fajarse a trabajar y es así como nosotros nos sacrificamos. Nosotros nos apretábamos el estómago. Nos limitábamos en todo para ir ahorrando. Tú te das cuenta cómo hemos progresado, ya tenemos nuestra casita, nuestro negocio, nuestro carro. Pero después de 30 años de trabajar como negro, decimos aquí.

B: -¿Cuál era su proyecto en su primer viaje?

O: -¿Cuál era mi proyecto? Se puede decir que mi ilusión, porque cuando nosotros venimos de nuestro pueblo natal venimos con ilusiones. Mi ilusión era comprarle una lavadora a mi mamá, comprarle sus utensilios, porque yo veía que mi mamá lavaba en una piedra. No tenía todos los equipos adecuados: lavadora, licuadora, refrigerador, televisión, todos los aparatos que existen. $Y$ aparte de eso, mi ilusión era una camioneta.

Los huaquechulenses delinean claramente el tránsito del trabajo escaso en el mercado agrícola y la vida de puro trabajo en Nueva York, contrastando su condición "a expensas" con una nueva posición en el trabajo en donde "lo mandan a uno"44. La vida de puro trabajo en Estados Unidos es descrita por los migrantes como una vida rutinaria, adaptada a los ritmos

\footnotetext{
42 Josefina (entrevista 2004, Huaquechula, Puebla).

43 Olegario (entrevista 2004, Nueva York).

${ }^{44}$ Del mismo modo que "trabajar para matarse", "ir a que lo manden a uno", es algo común en el discurso de los huaquehulenes. Esta frase la registré en diversas pláticas informales y entrevistas cuando las y los migrantes se referían al trabajo en Nueva York.
} 
intensos de las jornadas laborales sin horario fijo ni días de descanso, a la necesidad de tener más de un trabajo y a la manera en que "hacer la vida" depende por completo del trabajo asalariado. "Que lo manden a uno" señala una condición de trabajador donde se reconoce plenamente que el fruto del trabajo y la riqueza producida es para otros. Diríamos en términos de Yann Moulier Boutang ${ }^{45}$ que con estos discursos describen una transición hacia el trabajo dependiente, es decir, aquel en donde sólo tienen su capacidad de trabajo para vivir.

La vida de puro trabajo es una valoración crítica que sólo es posible hacerla desde la condición de migrantes que han transitado de formas de vida no plenamente subsumidas al capital, en varios sentidos. Muchos de los migrantes del primer cohorte generacional de Huaquechula experimentaron el trabajo en el campo laborando para sus familias, es decir, sin que mediara el trabajo asalariado y participaron de relaciones de cooperación al interior de los grupos domésticos y en la localidad. Aún para la reproducción de la vida, las mujeres en Estados Unidos tienen que pagar trabajos de cuidado que en su pueblo eran trabajos de cooperación entre mujeres de grupos extensos familiares. En Nueva York la cooperación entre familiares y vecinos pasa por la mediación del dinero. En México, el trabajo asalariado de los grupos domésticos campesinos se conjugó por años con el trabajo de subsistencia y cooperación fuera de las relaciones salariales ${ }^{46}$.

La crítica explícita que realizan los migrantes a lo que llaman "la vida de puro trabajo" donde "lo mandan a uno" se establece simultáneamente a la línea de fuga del "trabajo a expensas" propio de sus lugares de origen, lo que resignifica lo que podríamos pensar como una transición lineal de una clase de campesinos a trabajadores disciplinados del sector servicios en Nueva York. Lo que quiero sugerir es que al mismo tiempo que podemos prefigurar una línea de fuga del trabajo degradado, como un motor subjetivo operando en el movimiento migratorio, observamos formas de vida que trazan líneas de escape de la vida de puro trabajo, las cuales pueden constatarse en la manera en que los migrantes recrean relaciones que desafían las formas de vida del trabajo asalariado, a través de los diferentes vínculos y prácticas sociales transfronterizas que re-inventan las maneras de habitar las nuevas relaciones sociales de la metrópoli, a la vez que construyen otras formas de modernidad en las comunidades de donde salieron ${ }^{47}$.

\section{Conclusiones}

Haciendo eco de la propuesta de la autonomía de las migraciones, en este ensayo me he asomado a la subjetivación de las formas de subordinación al trabajo y las formas de vida asociados a éste a través de un estudio de caso etnográfico. He expuesto el carácter embridado del trabajo de los migrantes en los restaurantes, en el que los procesos de subjetivación que realizan individual y colectivamente los trabajadores son centrales para que la ilegalización tenga efectos en la disciplina y explotación del trabajo. Me ha parecido importante subrayar

\footnotetext{
45 MOULIER-BOUTANG, Yann, "De la esclavitud al trabajo asalariado...", op.cit.

${ }^{46}$ De ninguna manera esta afirmación implica que no hubiera conflicto o relaciones de dominio en estas formas de vida anclada al trabajo agrícola, sólo se trata de remarcar el hecho de que esta experiencia existe y es recuperada en las subjetividades que los migrantes construyen en sus nuevas formas de vida.

${ }^{47}$ Aquí me refiero a prácticas de retorno simbólico a la vida social de la comunidad, que incluyen proyectos de vivienda, proyectos educativos de los hijos en la comunidad, participación en las fiestas tradicionales de las familias y las comunidades, a través de distintos mecanismos.
} 
cómo esta combinación entre elementos despóticos y de libertad acotada, pero presente, en los mercados de trabajo, produce la disposición de una mano de obra explotable en el sector de los restaurantes en Nueva York.

La fuga es vista en la experiencia de los migrantes en los restaurantes como el margen de libertad que ejercen para mejorar sus condiciones laborales dentro del cerco que la ilegalización les impone. La perspectiva de análisis de la tensión entre trabajo abstracto y trabajo vivo se amplía y profundiza en los testimonios de los migrantes alrededor de los procesos subjetivos presentes en la subordinación y escape a la rutina diaria y el trabajo embridado en los Estados unidos. El artículo ha presentado cómo el antagonismo social está presente en el movimiento social y subjetivo de ida y vuelta que realizan los migrantes, entre la imposibilidad de vivir más del campo y la vida del trabajo plenamente bajo el mando del capital.

Parece muy importante desde este punto de vista conectar las experiencias laborales de los migrantes más allá de los espacios de trabajo y leer su experiencia social dentro de un proceso abierto entre captura y fuga, que encarna en las propias lógicas de construcción de la vida social de los migrantes; es decir, la tensión social constitutiva del capitalismo también los atraviesa individual y colectivamente, y también es un proceso abierto.

El trabajo de los migrantes se presenta en el presente capitalista como una de esas formas de trabajo embridado que han sido indispensables para la disponibilidad de la fuerza de trabajo y que son relevantes para los mercados de trabajo como en los que se desempeñan los huaquechulenses. Para Mezzadra el capitalismo global es un régimen en transición y, por tanto, el proceso de traducción de todas las formas heterogéneas de vida y subjetividades que constituyen el trabajo vivo es un proceso en marcha. La oposición de lo que llama la composición del trabajo libre en el mundo contemporáneo al proceso de abstracción del trabajo es un proceso abierto ${ }^{48}$.

\section{Bibliografía}

AQUINO, Liliana, "La migración de jóvenes zapatistas a Estados Unidos como desplazamiento geográfico, político, subjetivo" en European Review of Latin American and Caribbean Studies / Revista Europea de Estudios Latinoamericanos y del Caribe, No 92, Centrum voor Studie en Documentatie van Latijns Amerika (CEDLA), 2012, pp.3-22.

ARAGONÉS, Ana María y SALGADO, Uberto, "La migración en los albores del siglo XXI. El caso México Estados Unidos" en Crítica y Emancipación, año II, Vol. 1, primer semestre, 2011.

BASCH, Linda y GLICK SCHILLER, Nina, Nations Unbound. Transnational Projects, Postcolonial Predicaments and Deterritorialized Nation States, Gordon and Breach, Nueva York, 1994.

BERHARDT, Annete, MC GRATH, Siobhán y DE FILIPPIS, James, Unregulated work in Global City. Employment and labor law violations in New York City, Brenner Center for Justice, New York University School of Law, Nueva York, 2007.

CANALES, Alejandro, "Migración y trabajo en la era de la globalización: el caso de la migración mexicana a Estados Unidos en la década de 1990" en Papeles de población, Vol. 11, No 43-44, 2002, pp. 149-172.

CASTLES, Stephen H. de H. y MILLER, J. Mark, La era de la migración. Movimientos internacionales de la población en la era moderna, Universidad de Zacatecas, INM, Miguel Ángel Porrúa, México, 2004.

${ }^{48}$ Ibidem. 
CASTLES, Stephen H. de H. y MILLER, J. Mark, The new age of migration. International population movements in the modern era, Palgrave MacMillan, Londres, 2014 [5a edición].

CORDERO, Blanca L., Ser Trabajador Transnacional. Hegemonía, clase y cultura en un circuito migratorio internacional, BUAP, CONACYT, México, 2007.

DE GENOVA, P., Nicholas, "Migrant 'Illegality' and deportability in everyday life" en Annual Review Anthropology, Vol. 31, Universidad de California, 2002, pp. 419-447.

DE GENOVA, P., Nicholas, "The everyday civil war: Migrant working men, within and against capital" en Ethnography, Vol. 7, No 2, Junio 2006, pp. 243-267.

ESTÉVEZ, L. Ariadna, "La relación estructural entre la globalización y la migración. Implicaciones para una ciudadanía universal" en Foro Internacional, Vol. XLIX, No 3, México, 2009, pp. 559-594.

GLEDHILL, John, Neoliberalism, transnationalism and rural poverty. A case study of Michoacán, México, Westview, Estados Unidos, 1995.

GOLDRING, Luin, "Blurring Borders: Constructing Transnational Community in the Process of Mexico-US Migration" en Research in Community Sociology, Vol. 6, Jai Press, 1996, pp. 69-104.

GUZMÁN, A., José, ¿Ilegal-es? vivencias de Huaquechula en un barrio latino y un suburbio en Nueva York dentro de relaciones hegemónicas y flexibilidad laboral, dirigida por Blanca Laura Cordero Díaz, ICSYH-AVP-BUAP, México, 2014.

HARVEY, David, La condición de la posmodernidad. Investigación sobre los orígenes del cambio cultural, Amorrortu Editores, Buenos Aires, 1998 [1990].

HARVEY, David, El nuevo imperialismo, Akal, Madrid, 2003.

HOLLOWAY, John, Clase = Lucha. Antagonismo social y marxismo crítico, BUAP, Herramienta, MéxicoArgentina, 2004.

HONDAGNEU-SOTELO, Pierrette, Gendered Transitions: Experience of Inmigration, University of California Press, Estados Unidos, 1994.

MARX, Karl, El capital. Crítica de la economía política. Tomo I. El proceso de producción de capital, Siglo XXI, México, 2001 [1975].

MEZZADRA, Sandro, "The Right to Escape" en Ephemera, Vol. 4, No 3, 2004, p. 270.

MEZZADRA, Sandro, Derecho de fuga. Migraciones, ciudadanía y globalización, Traficantes de sueños, Madrid, 2005.

MEZZADRA, Sandro, "Living in transition" en Transversal, 11-07, 2007: http://translate.eipcp.net/ transversal/1107 [Consultado 20 de noviembre de 2015].

MEZZADRA, Sandro, "¿Cuántas historias del trabajo? Hacia una teoría del capitalismo poscolonial" en Transversal, Vol. 01, No 12, 2012: http://eipcp.net/transversal/0112/mezzadra/es [Consultado 2 de abril de 2016]

MOLINERO, Yoan y AVALLONE, Gennaro, "Produciendo comida y trabajo baratos: migraciones y agricultura en la ecología mundo capitalista" en Relaciones Internacionales, No 33, 2016: http://www.relacionesinternacionales.info/ojs/article/view/731.html [Consultado 8 de abril de 2017]

MOULIER-BOUTANG, Yann, De la esclavitud al trabajo asalariado. Economía histórica del trabajo asalariado embridado, Akal, Madrid, 2006.

PARRA, José María y GÁMEZ, Emilia, "Situación de la fuerza de trabajo en Estados Unidos" en BENENCIA, R., HERRERA, F. y LEVINE E., (Coords.), Ser migrante latinoamericano, ser vulnerable, trabajar precariamente, ANTHROPOS, UAM, México, 2012, pp.113-136.

PRIES, Ludger, Migration Transnational Social Space, Ashgate Publishing Ltd, Inglaterra, 1999.

SASSEN, Saskia, Contrageografías de la globalización. Género y ciudadanía en los circuitos transfronterizos, Madrid, España, Traficantes de Sueños, 2003. 


\section{RELACIONES INTERNACIONALES}

Revista académica cuatrimestral de publicación electrónica Grupo de Estudios de Relaciones Internacionales (GERI) Universidad Autónoma de Madrid, España

www.relacionesinternacionales.info

ISSN 1699 - 3950

ff facebook.com/RelacionesInternacionales

twitter.com/RRInternacional 